\title{
Determination of Acetyl Salicylic Acid in Aspirin tablets
}

\author{
Lana Mohammed Ali \\ Chemistry Department \\ College of Education \\ University of Sulaimani \\ Sulaimani, Iraq \\ Lana.ale@univsul.edu.iq
}

\author{
Mariwan Abdulla Hama Salih \\ Medical Laboratory Department \\ Technical College of Health \\ Sulaimani Polytechnic University \\ Sulaimani, Iraq \\ Mariwan.abdulla@spu.edu.iq
}

\author{
Omed Ismael Hayder \\ Chemistry Department \\ College of Science \\ University of Sulaimani \\ Sulaimani, Iraq \\ Omed.ismael@univsul.edu.iq
}

\author{
Volume 4 - Issue 2 \\ December 2018 \\ DOI: \\ 10.24017/science.2019. \\ 2.15
}

Received:

02 September 2019

Accepted:

01 December 2019

\begin{abstract}
Drug analysis is an important method for determination of active components of any therapeutic drugs. HPLC, Spectrometry, Direct titration and Back-titration are common effective techniques in drug analysis. They were used in this study in comparative way for determination of the correct amount of acetyl salicylic acid in aspirin formulations. The aim of this study is to analysis of aspirin and compares both Direct titration and Back-titration techniques to the standard HPLC technique in order to find alternative, easy and cheaper procedure to assess the quality of active components of medications aspirin in particular in Sulaimani city. Additionally Spectrophotometric technique were also used and compared with the standard HPLC method. The samples were collected from different local drug stores in which distribute medications to pharmacies and they were from different companies. The analyses were performed after preparing solution from each of the samples with standard solution for titration procedures. Both direct and back-titration techniques were used to find the concentration of active components in aspirin samples then compared with the data from standard HPLC as a reference value. The study showed that those companies which provide medications to this region were used standard amount of acetyl salicylic acid in aspirin tablets. The result from Spectrophotometric method showed more accurate than both direct and indirect titration when compared to the reference value from standard HPLC technique due to the high rate of accuracy and precision of this method. However, the result also showed some inconsistent data in terms of the back titration compared to direct titration due to the inaccuracy in back titration. This study concluded with the necessity for quality control to use all these techniques for monitoring all medications which interring this region.
\end{abstract}

Keywords: Drug analysis, HPLC, Titration, Back-Titration, Aspirin, Spectrophotometer, Acetyl Salicylic Acid. 


\section{INTRODUCTION}

Drug analysis has a long history for quality control of the drugs from different source of productions through the worldwide. In order to control the quality of drugs to save the life of patient that they supposed to use drugs as a treatment, it is important to find an alternative procedure to determine the quality of drugs compared to the standard HPLC (High Performance Liquid Chromatography) method.

HPLC is a most common and standard method that were used for drug analysis from several years ago.[1] Drug discovery and manufacture needs several steps before using for treatment. For drug analysis there are other methods have been used but they were not continuing for some limitations, including long procedure, high cost, need more staff and time consumption. The reversed phase HPLC technique previously used successfully for analysis of cocaine and it's metabolites in urine samples and plasma as well, the results from this method were found consistence with previous recorded results. Here the method of titration (direct and indirecttitration) and Spectrophotometric method was tried to ensure the quality of aspirin currently taken by patient and to compare the results and the possibility to replace HPLC method. The HPLC technique is standard but the high cost of the machine make limitation for some laboratories.

Aspirin, an acetyl derivative of salicylic acid, is a white crystalline, a weak acid substance its melting point $135^{\circ} \mathrm{C} .[2]$ Acetyl salicylic acid decomposed quickly when dissolved in a solutions of ammonium acetate or carbonates, citrates and hydroxides of metals.[2] Acetylsalicylic acid is quite stable in dry air but it will hydrolysis to acetic acid and salicylic acid in the presence of humidity. Nowadays, aspirin is the most used salicylate derivative.[3] Aspirin (acetyl salicylic acid) is considered as intriguing anti-inflammatory and analgesic-pyretic drug.[4] In addition, aspirin in a low-dose has an anticoagulant potential and is used in long term to reduce the risk of heart attack. Aspirin is the first known non-steroidal antiinflammatory drugs (NSAID), and it interfere the action of some drugs, such as warfarin and methotrexate.[2, 5] Aspirin considered the most widely used pain relievers in patients with mild to moderate pain, migraines, and fever.[6] People with headaches, joint pain, or other aches in their body, can took aspirin or another antiinflammatory drug. However several fruits, vegetables, and herbs contain natural aspirin such as Eggplant, Figs, Grape fruit Grapes, pistachios, pine nuts, almonds, etc. $[3,7]$

Medications can be analysed by titration and several other techniques such as titration. Titration process is performed by gradually addition of standard solution (i.e. a solution of known concentration) to the solution of analyte or unknown concentration. The addition is stopped when the equivalence point is reached. It occurs when moles of titrant equals moles of analyte according to the balanced equation. Back titration: A back titration is a titration method where the concentration of an analyte is determined by reacting with a known amount of excess reagent. The remaining excess reagent is then titrated with another second reagent. The second titration's results show how much of the excess reagent was used in the first titration and the original analyte concentration can then be calculated. In a back titration, a known amount of reagent is added to a solution and allowed to react, and the excess is titrated. A back titration may also be called an indirect titration.[8]

Spectrophotometric method have been used previously by some researchers for determination of ASA in aspirin and other medications such as paracetamol, Clopidogrel,[9-10] and some analgesic drugs were also analyzed,[11] they were showed that this method was quite accurate and not showed any evidence of impurities interference during application of the method. The method is quit straight forward and more accessible compared to titration and other procedures. 
The reviewed literature revealed that other procedures have been used for quantitative determination of aspirin by the methods of coupling reaction,[12] HPLC,[13] UV. Visible spectrophotometry,[9-10] Electrochemistry,[12] FIA Automatic Flow Injection Analysis,[14] Complexometry,[15] and Flourimetry.[16] The comparative study of both Spectrophotometry and HPLC reported that the data obtained were in reference range.[17] In general these methods were used also for different formulations, such as Paracetamol.[10] and Clopidogrel.[18] Several researcher from all over the world used these methods to determine the quality and quantity of active component in medicine especially aspirin.[19] Here in this study, the focus were on quantitative determination of Acetyl Salicylic Acid in Aspirin or the purity of aspirin that currently present in the local market in Sulaimani city, and distributed for public and private pharmacies. The aim of this work is also to evaluate the quality of the aspirin and its availability in high quality will be assessed. The direct and back-titration techniques [8] as well as spectrophotometric method will be used and comparing to standard HPLC techniques in term of the capacity and accessibility of these techniques that could be used for determination purity of Aspirin.

\section{METHODS AND MATERIALS}

All Chemicals, reagents and glassware that were used in this study are readily available in the laboratories, or bought and borrowed from other laboratories from this region. They were from Sigma-Aldrich or Fisher companies. Both titration and back-titration techniques were used and compared with standard HPLC method. The Spectrophotometer in this research was used for analysis of the samples.

\subsection{Sample collection}

The samples were collected randomly from local drug stores and from pharmacies in Sulaimani city. The sample size was nineteen samples and from nineteen different local and international companies.

\subsection{Solutions preparation Methods and Calculations}

The samples were prepared by using distilled water and ethanol, standard solution were prepared from each samples then used for titration with freshly prepared standard solution of reagent then titrated by classical titration techniques with end point detector by indicator. (acid -base titration procedure).[8,20] Each sample of aspirins were dissolved in aqueous ethanol because aspirin itself not dissolve well in water, phenolphthalein indicator was used to detect end point. The titrations were done with standard solution of sodium hydroxide $\mathrm{NaOH}$, and then the correct volumes were recorded. Standard solution of $\mathrm{HCl}$ was prepared from standardization by borax. Standard solution of $\mathrm{NaOH}$ was prepared from standardization by standard $\mathrm{HCl}$ solution. The percentage of purity was calculated for each sample by the following equation:

$$
\% \text { Purity of aspirin in the sample }=\frac{\text { actual mole of aspirin }}{\text { theoritical mole of aspirin }}
$$

The samples weight were taken one by one then grinded to be in powder form, the weighed samples were dissolved in ethanol then completed in $100 \mathrm{ml}$ volumetric flask $(1 \mathrm{gm} / 1 \mathrm{gm})$. The actual mole of aspirin is the mole of acid that actually reacted with the standard $\mathrm{NaOH}$ solution. Therefore by considering the samples of aspirin are pure the calculations of each tablet are theoretical mole of aspirin. $\mathrm{Fecl}_{3}$ has been used for spectrophotometric determination of ASA in aspirin samples for the formation of colored complex to read by the spectrophotometer. For this purpose a series of solution was prepared for different concentration of ASA, after formation of complex with $\mathrm{Fe}^{+3}$ the absorbance were read at $530 \mathrm{~nm}$. 


\section{RESULTS AND DISCUSSION}

The Table 1 and Table 2 showed the comprehensive data obtained from direct and indirect titration respectively for analyzed aspirin tablets from various sources, and for each of them the reference value from HPLC were provided in order to observe the difference in the result obtained from the techniques were used. The percentage of labeling for each tablets were also showed. The tablet of aspirin from Iranian company entry 1 in Table 1 showed a very little different value from the result of direct titration and back-titration entry 1 in Table 2 and the same with standard HPLC technique (reference value), this result can be considered by the good value, because the value considered very close to the HPLC data. However, for some companies the data were found very different when compared to the HPLC data, for example entries 11, 15, 18 in Table 1 or these companies might produce low quality of aspirin to the Kurdistan market.

Table 1: The data of titration and HPLC procedures

\begin{tabular}{clcccc}
\hline Entry & \multicolumn{1}{c}{ Company Name } & $\begin{array}{c}\text { Weight } \\
\text { gm/ tablet }\end{array}$ & $\begin{array}{c}\text { Percent } \\
\text { labeling }\end{array}$ & \% Titration & HPLC \\
\hline $\mathbf{1}$ & A.S.A Iran $100 \mathrm{mg}$ & 0.1182 & 84.6 & 72 & 67.85 \\
\hline $\mathbf{2}$ & A.S.A UK $300 \mathrm{mg}$ & 0.3389 & 88.5 & 71 & 69.4 \\
\hline $\mathbf{3}$ & A.S.A Iraq $100 \mathrm{mg}$ & 0.1314 & 76 & 65.3 & 59.3 \\
\hline $\mathbf{4}$ & A.S.A Iran $100 \mathrm{mg}$ & 0.2799 & 36 & 31.6 & 29.7 \\
\hline $\mathbf{5}$ & A.S.A GI $5 \mathrm{mg}$ & 0.1974 & 38 & 31 & 33.9 \\
\hline $\mathbf{6}$ & A.S.A EU $100 \mathrm{mg}$ & 0.1265 & 79 & 53.75 & 59.9 \\
\hline $\mathbf{7}$ & A.S.A London $300 \mathrm{mg}$ & 0.3355 & 90 & 73.6 & 79.4 \\
\hline $\mathbf{8}$ & A.S.A Boots GI $75 \mathrm{mg}$ & 0.19996 & 38 & 37 & 35.7 \\
\hline $\mathbf{9}$ & A.S.A COX $300 \mathrm{mg}$ & 0.34136 & 87.7 & 70 & 89.3 \\
\hline $\mathbf{1 0}$ & A.S.A Pars Iran $81 \mathrm{mg}$ & 0.16093 & 49.7 & 42 & 47.8 \\
\hline $\mathbf{1 1}$ & A.S.A Polspirin $100 \mathrm{mg}$ & 0.1581 & 63.2 & 50.4 & 75.8 \\
\hline $\mathbf{1 2}$ & A.S.A Bulgaria $100 \mathrm{mg}$ & 0.16413 & 61 & 52 & 49.5 \\
\hline $\mathbf{1 3}$ & A.S.A Austria $100 \mathrm{mg}$ & 0.21466 & 46.5 & 39.2 & 45.4 \\
\hline $\mathbf{1 4}$ & A.S.A Romania $100 \mathrm{mg}$ & 0.1807 & 55 & 54.6 & 54.4 \\
\hline $\mathbf{1 5}$ & A.S.A India $81 \mathrm{mg}$ & 0.1831 & 44.2 & 33.6 & 40.6 \\
\hline $\mathbf{1 6}$ & A.S.A LD USA $81 \mathrm{mg}$ & 0.12202 & 44 & 56.5 & 62.4 \\
\hline $\mathbf{1 7}$ & A.S.A Jusparin $81 \mathrm{mg}$ & 0.12485 & 64 & 59 & 64 \\
\hline $\mathbf{1 8}$ & A.S.A Erbil $75 \mathrm{mg}$ & 0.0965 & 77.7 & 60 & 50.1 \\
\hline $\mathbf{1 9}$ & $\begin{array}{l}\text { A.S.A Kardikern Spain } 100 \\
\text { mg }\end{array}$ & 0.2637 & 38 & 58 & 52 \\
\hline A.S.A Acety & & & & \\
\hline
\end{tabular}

A.S.A=Acetyl Salicylic Acid; $\mathrm{LD}=$ Low Dose

The best results can be observed for the product of Romania (Table 1, entry 14), because the result from direct titration and reference value from HPLC were nearly the same value (54.6, 54.4 respectively) and also the value of back-titration is nearly similar (50). The product of Iraqi company (Table 1 and Table 2, entry 18) were showed little different in amount of A.S.A in their product for both titration and back-titration (60, 58.8 respectively) compared to the reference value of HPLC (50.1), this difference could be due to present of lower concentration of the acetyl salicylic acid in the product of this company. 
Table 2: The results of Back-titration and HPLC data

\begin{tabular}{clccccc}
\hline Entry & \multicolumn{2}{c}{ Company Name } & $\begin{array}{c}\text { Weight gm/ } \\
\text { tablet }\end{array}$ & $\begin{array}{c}\text { Percent } \\
\text { labeling }\end{array}$ & $\begin{array}{c}\text { \% Back- } \\
\text { titration }\end{array}$ & HPLC \\
\hline $\mathbf{1}$ & A.S.A Iran $100 \mathrm{mg}$ & 0.1182 & 84.6 & 69.7 & 67.85 \\
\hline $\mathbf{2}$ & A.S.A UK $300 \mathrm{mg}$ & 0.3389 & 88.5 & 67.7 & 69.4 \\
\hline $\mathbf{3}$ & A.S.A Iraq $100 \mathrm{mg}$ & 0.1314 & 76 & 68.8 & 59.3 \\
\hline $\mathbf{4}$ & A.S.A Iran $100 \mathrm{mg}$ & 0.2799 & 36 & 37.2 & 29.7 \\
\hline $\mathbf{5}$ & A.S.A GI & \multicolumn{1}{c}{$5 \mathrm{mg}$} & 0.1974 & 38 & 32.2 & 33.9 \\
\hline $\mathbf{6}$ & A.S.A EU $100 \mathrm{mg}$ & 0.1265 & 79 & 68.4 & 59.9 \\
\hline $\mathbf{7}$ & A.S.A London & $300 \mathrm{mg}$ & 0.3355 & 90 & 53.2 & 79.4 \\
\hline $\mathbf{8}$ & A.S.A Boots GI $75 \mathrm{mg}$ & 0.19996 & 38 & 33.8 & 35.7 \\
\hline $\mathbf{9}$ & A.S.A COX & $300 \mathrm{mg}$ & 0.34136 & 87.7 & 54.6 & 89.3 \\
\hline $\mathbf{1 0}$ & A.S.A Pars Iran $81 \mathrm{mg}$ & 0.16093 & 49.7 & 36 & 47.8 \\
\hline $\mathbf{1 1}$ & A.S.A Polspirin $100 \mathrm{mg}$ & 0.1581 & 63.2 & 68.3 & 75.8 \\
\hline $\mathbf{1 2}$ & A.S.A Bulgaria & $100 \mathrm{mg}$ & 0.16413 & 61 & 42.11 & 49.5 \\
\hline $\mathbf{1 3}$ & A.S.A Austria & $100 \mathrm{mg}$ & 0.21466 & 46.5 & 45.92 & 45.4 \\
\hline $\mathbf{1 4}$ & A.S.A Romania $100 \mathrm{mg}$ & 0.1807 & 55 & 50 & 54.4 \\
\hline $\mathbf{1 5}$ & A.S.A India & $81 \mathrm{mg}$ & 0.1831 & 44.2 & 33.2 & 40.6 \\
\hline $\mathbf{1 6}$ & A.S.A LD USA $81 \mathrm{mg}$ & 0.12202 & 44 & 57.8 & 62.4 \\
\hline $\mathbf{1 7}$ & A.S.A Jusparin $81 \mathrm{mg}$ & 0.12485 & 64 & 51.4 & 64 \\
\hline $\mathbf{1 8}$ & A.S.A Erbil & $75 \mathrm{mg}$ & 0.0965 & 77.7 & 58.8 & 50.1 \\
\hline $\mathbf{1 9}$ & A.S.A Kardikern Spain 100 & 0.2637 & 38 & 58.5 & 52 \\
\hline A.S.A Acetyl Salicylic Acid; LD= Low Dose & & & \\
\hline
\end{tabular}

The result of back-titration for the sample of aspirin from London (Table 2, entry 7) showed (53.2) which is not very accurate compared to titration value in Table 1 entry 7 which is 73.6 and reference value 79.4 , as it can be seen again in entry 9 and entry 17 . These results from the current technique considered better results compared to those from voltammetry[21] method regarding accuracy. Conversely, the accuracy and precision of both type of titration method were found very low compared to HPLC method. The result also stated that there are some differences in the product of these companies. Interestingly, despite the variation in the value of most brands but they can be considered in the official ranges [9] and most of the results shown here can be considered close to the reference value except those discussed earlier (Table 1 and Table 2 entries 7 and 9).

The Figure 1 showed the absorbance of the prepared series of solution from aspirin sample at $530 \mathrm{~nm}$ of maximum wave length, the linear correlation obtained is showed here for different concentration of ASA in aspirin samples. The maximum absorbance was obtained for optimum concentration at $1 \times 10^{-2} \mathrm{M}$ of each aspirin samples. 


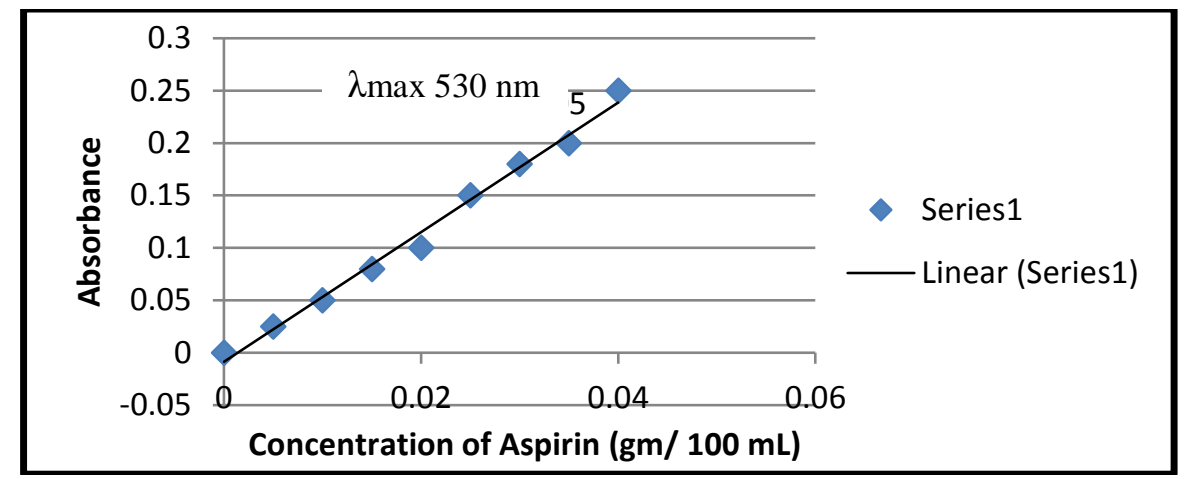

Figure 1: Spectrophotometric calibration curve.

The data of spectrophotometric analysis method showed in Table 3, these data can be described by better data that were obtained for aspirin analysis than both types of titrations, but not accurate as the data obtained from standard HPLC method, due to stability of the colored solutions of the formulations. The average difference between this method and HPLC or labeling data were found between 0.08 to 19 digit numbers entry 13 and 6, the large difference can be explained by the low quality of some aspirin samples and the high quality of some of the samples in reverse.[18]

Table 3: The results of Spectrophotometric method and HPLC data

\begin{tabular}{|c|c|c|c|c|c|}
\hline Entry & Company Name & $\begin{array}{c}\text { Weight gm/ } \\
\text { tablet }\end{array}$ & $\begin{array}{l}\text { Percent } \\
\text { labeling }\end{array}$ & $\%$ Spect. & HPLC \\
\hline 1 & A.S.A Iran $100 \mathrm{mg}$ & 0.1182 & 84.6 & 67.2 & 67.85 \\
\hline 2 & A.S.A UK $300 \mathrm{mg}$ & 0.3389 & 88.5 & 64.5 & 69.4 \\
\hline 3 & A.S.A Iraq $100 \mathrm{mg}$ & 0.1314 & 76 & 57.9 & 59.3 \\
\hline 4 & A.S.A Iran $100 \mathrm{mg}$ & 0.2799 & 36 & 25.9 & 29.7 \\
\hline 5 & A.S.A GI $5 \mathrm{mg}$ & 0.1974 & 38 & 38.7 & 33.9 \\
\hline 6 & A.S.A EU $100 \mathrm{mg}$ & 0.1265 & 79 & 63.3 & 59.9 \\
\hline 7 & A.S.A London $300 \mathrm{mg}$ & 0.3355 & 90 & 75.8 & 79.4 \\
\hline 8 & A.S.A Boots GI $75 \mathrm{mg}$ & 0.19996 & 38 & 35.1 & 35.7 \\
\hline 9 & A.S.A COX $300 \mathrm{mg}$ & 0.34136 & 87.7 & 90.3 & 89.3 \\
\hline 10 & A.S.A Pars Iran $81 \mathrm{mg}$ & 0.16093 & 49.7 & 48.5 & 47.8 \\
\hline 11 & A.S.A Polspirin $100 \mathrm{mg}$ & 0.1581 & 63.2 & 75.1 & 75.8 \\
\hline 12 & A.S.A Bulgaria $100 \mathrm{mg}$ & 0.16413 & 61 & 45.7 & 49.5 \\
\hline 13 & A.S.A Austria $100 \mathrm{mg}$ & 0.21466 & 46.5 & 42.2 & 45.4 \\
\hline 14 & A.S.A Romania $100 \mathrm{mg}$ & 0.1807 & 55 & 55.1 & 54.4 \\
\hline 15 & A.S.A India $\quad 81 \mathrm{mg}$ & 0.1831 & 44.2 & 45.3 & 40.6 \\
\hline 16 & A.S.A LD USA $81 \mathrm{mg}$ & 0.12202 & 44 & 61 & 62.4 \\
\hline 17 & A.S.A Jusparin $81 \mathrm{mg}$ & 0.12485 & 64 & 64.5 & 64 \\
\hline 18 & A.S.A Erbil $75 \mathrm{mg}$ & 0.0965 & 77.7 & 52.4 & 50.1 \\
\hline 19 & $\begin{array}{l}\text { A.S.A Kardikern Spain } 100 \\
\text { mg }\end{array}$ & 0.2637 & 38 & 37.9 & 52 \\
\hline
\end{tabular}

A.S.A=Acetyl Salicylic Acid; LD= Low Dose; Spect.= Spectrophotometric method

From the figure and table 3 can be observed that the fact of the low quality of some aspirin available in present time at local market. For example entry 18 when compared with the percent of labeling, the difference is very large but it is very close to the reference value from HPLC method. While for entry 19 there is no large difference between percent of labeling with practical value but high difference with HPLC reference. 


\section{CONCLUSION}

In conclusion, the data obtained from both titration and back-titration methods in determination of the purity of aspirin were in acceptable range and comparable with the data from the standard HPLC method. This means that the quality of aspirin that currently distributed or used were good except some of them have low quality in term of purity or the amount of ASA. This also means these methods can be used as an alternative way for quality control of medications which inter the region. However, both types of titration method also showed not easily to use and technically difficult when compared to HPLC. But the access for titration and back-titration methods were found easier when compared to the voltammetry. The results from spectrophotometric technique showed that the method is more economically suitable and the data are more accurate due to high rate of accuracy. The data from spectrophotometric method also showed that the quality of the aspirin in Sulaimani local drug stores was good even the product of Erbil showed the data in reference range. These advantages of spectrophotometric method encouraged to be considered for quality control of drugs.

\section{REFERENCE}

[1] B. Nikolin, B. Imamović, S. Medanhodžić-Vuk, and M. Sober, "High performance liquid chromatography in pharmaceutical analyses," Bosnian Journal of Basic Medical Sciences, vol. 4, 2004.

[2] K. Schrör, Acetylsalicylic Acid. Germany: British Library Cataloguing-in-Publication Data, 2009.

[3] P. Silverman, M. Seskar, D. Kanter, P. Schweizer, J. P. Metraux, and I. Raskin, "Salicylic Acid in Rice Biosynthesis, Conjugation and Possible Role," Plant Physiology, vol. 108, pp. 633-639, 1995.

[4] Bayer Inc. (2014, Product Monograph. Available: www.healthcanada.gc.ca/medeffect

[5] M. C. Koester, "An overview of the physiology and pharmacology of Aspirin and Nonsteroidal Antiinflammatory Drugs," Journal of Atheletic Training, vol. 28, pp. 252-259, 1993.

[6] C. S. Kwok and Y. K. Loke, "Critical overview on the Benefits and Harms of Aspirin," Pharmaceuticals, vol. 3, pp. 1491-1506, 2010.

[7] M. Yusuf, et al., "Salicylic Acid: Physiological Roles in Plants," ed, 2013, pp. 15-30.

[8] D. C. Harris, Quantitative Chemical Analysis, 7 ed., 2007.

[9] G. Motan and A. Pui, "Studies of different types of aspirin by spectrophotometric methods," ACTA CHEMICA IASI, vol. 22, pp. 155-164, 2014.

[10] G. Murtaza, et al., "Development of a UV-spectrophotometric method for the simultaneous determination of aspirin and paracetamol in tablets," Scientific Research and Essays vol. 6, 2011.

[11] A. M. El-Didamony, M. Z. Saad, and N. O. Saleem, "Spectrophotometric determination of some analgesic drugs in pharmaceutical formulations using N-bromosuccinimide as an oxidant," Journal of the Association of Arab Universities for Basic and Applied Sciences, vol. 17, pp. 43-50, 2015/04/01/ 2015.

[12] S. S. Mohamed, "Comparative Analytical Study for Determination of Acetyl salicylic Acid in Bulk and Pharmaceutical Formulations," Journal of Al-Nahrain University, vol. 16, pp. 1-10, 2013.

[13] M. H. Bhuyian, P. D. H. Rashid, A. Islam, and M. Tareque, "Development and Validation of Method for Determination of Clobetasol Propionate and Salicylic Acid from Pharmaceutical Dosage form by HPLC," British journal of Pharmaceutical Research, vol. 7, pp. 375-385, 2015.

[14] J. Fernández, M. Castro, and M. Valcárcel, "Automatic continuous on-line monitoring of salicylic acid and acetylsalicylic acid in pharmaceuticals," Journal of Automatic Chemistry, vol. 12, pp. 263-266, 1990.

[15] V. Martínez-Merino. (2007, Determination of the free Salicylic Acid concentration in Aspirin by forming $\mathrm{Fe}+3$ complexes Available: www.iupac.org/publications/cd/medicinal_chemistry/

[16] B. Scientific, "Fluorimetric Determination of Acetylsalicylic Acid in Aspirin," British Pharmacopeia, vol. $2,1993$.

[17] A. Sani, A. Ahmed, T. Alemika, M. A. Sani, A. Ojuolape, A. Sani, A. Bukola, S. Zakama, and I. Mohammed, "Comparative quantitaive analysis of different brands of $300 \mathrm{mg}$ Aspirin tablet marketed in Maiduguri Metropolitan Council (MMC)," International Journal of Pharma Sciences and Researc, vol. 3, 2012.

[18] R. T. Suhas Gurav, Vishali Salunkhe, Devprakash, Senthilkumar G.P., "Spectrophotometric Determination of Clopidogrel Bisulfate in Pharmaceutical formulations," American Journal of Pharmtech Research, vol. $1,2011$.

[19] S. Mitic, G. Miletic, A. Pavlović, S. Tošić, and S. Sunaric, "Quantitative Analysis of Acetylsalicylic Acid in Commercial Pharmaceutical Formulations and Human Control Serum Using Kinetic Spectrophotometr," Acta Chim. Slov. , vol. 55, pp. 508-515, 2008.

[20] Bellevue College. (2017, Titration of synthesised Aspirin. Available: https://www.bellevuecollege.edu/chemistry/courses/chem161/

[21] C. Cofan and C. Radovan, "Anodic Determination of Acetyl salicylic Acid at a Mildly Oxidized BoronDoped Diamond Electrode in Sodium Sulphate Medium," International Journal of Electrochemistry, 2011. 